\title{
Transatlantica
}

Revue d'études américaines. American Studies Journal

\section{A. Frund et H. Le Dantec-Lowry (éds). « Ecritures de l'histoire africaine américaine ».}

In Annales du Monde Anglophone (2ème sem 2003), n 18. L'Harmattan, : Paris, $185 \mathrm{p}$.

Alice Mills

\section{(2) OpenEdition}

Journals

Édition électronique

URL : http://journals.openedition.org/transatlantica/877

DOI : $10.4000 /$ transatlantica.877

ISSN : $1765-2766$

Éditeur

AFEA

Référence électronique

Alice Mills, «A. Frund et H. Le Dantec-Lowry (éds). « Ecritures de l'histoire africaine américaine ». », Transatlantica [En ligne], 1 | 2005, mis en ligne le 24 avril 2006, consulté le 29 avril 2021. URL : http:// journals.openedition.org/transatlantica/877 ; DOI : https://doi.org/10.4000/transatlantica.877

Ce document a été généré automatiquement le 29 avril 2021.

\section{(c) (i) $\odot$}

Transatlantica - Revue d'études américaines est mis à disposition selon les termes de la licence Creative Commons Attribution - Pas d'Utilisation Commerciale - Pas de Modification 4.0 International. 


\section{A. Frund et H. Le Dantec-Lowry (éds). « Ecritures de l'histoire africaine américaine ».}

In Annales du Monde Anglophone (2ème sem 2003), n 18. L'Harmattan, : Paris, $185 \mathrm{p}$.

\section{Alice Mills}

1 «Ecritures de l'histoire africaine américaine » dirigé par Hélène Le Dantec-Lowry et Arlette Frund s'inscrit dans la mouvance d'une remise en cause de l'histoire consensuelle, d'où le pluriel d'« écritures » auquel aurait pu prétendre l'ensemble du titre puisque le livre porte sur l'Amérique du Nord et sur celle de la Caraïbe.

2 L'ouvrage met en avant les bouleversements relativement récents qui ont affecté la conception de l'histoire et montre que celle-ci tient enfin compte de ceux qu'elle avait longtemps ignorés ; l'histoire des Africains Américains fait désormais partie intégrante de l'histoire américaine, et les directrices de publication ont choisi une approche transversale pour le dire, liant diverses formes d'écriture et d'événement.

3 Le livre, ouvert sur des articles de spécialistes d'histoire, de civilisation et de sociologie, se referme sur des études littéraires tandis qu'au centre de l'ouvrage les domaines de spécialité se mêlent comme en un creuset. Onze travaux variant les angles d'approche et les disciplines sont présentés en français ou en anglais.

4 La première étude, rédigée par Arlette Farge, examine le travail de l'historien désormais tenu de rendre compte du non-dit et de l'invisible puisque des éléments tels que le silence et l'émotion sont aujourd'hui inclus dans ses sources primaires. L'article annonce les multiples questions abordées par l'ouvrage.

5 A travers le cas particulier de la retranscription-ou ré écriture?-des propos enregistrés d'Hosea Hudson, une étude d'Hélène Christol judicieusement placée au cœur du livre pose elle aussi une question essentielle: comment traiter la diversité des sources de l'entreprise historique? 
6 «Ecritures de l'histoire africaine américaine» sera utile aux afro-américanistes confirmés et aux non spécialistes dans la mesure où le livre suggère des pistes de réflexion inhabituelles tout en offrant un rappel des faits importants: les écrits de l'historienne Arlette Farge sur les archives du XVIIIème siècle et ceux du sociologue John Brown Childs sur l'apport des Indiens et des hispaniques dans la célébration de Black History Month englobent et franchissent les frontières de la communauté noire. D'autres travaux, centrés sur le réexamen des faits et de l'historiographie, mettent l'accent sur les manières variées dont, au cours des époques, on a présenté l'histoire des Africains Américains: Hélène Le Dantec-Lowry se penche sur l'écriture de cette histoire après les années soixante, Werner Sollors, spécialiste de la communauté noire, examine le passage des études africaines américaines, autrefois marginales, à la position centrale qu'elles occupent aujourd'hui et le sociologue Loic Wacquant propose une lecture de la prison comme substitut du ghetto. Des chants d'esclaves entendus pendant la guerre de Sécession et des illustrations d'Edward Windsor Kemble, respectivement examinés par Geneviève Fabre et Claire Parfait, proposent des réflexions sur les représentations qui se démarquent du texte écrit mais lui restent conjointes.

7 Les études littéraires présentées par l'ouvrage confirment la capacité de l'imaginaire non seulement à transcrire les « expériences situées hors de la portée de notre champ de connaissances" mais encore à le faire parfois mieux que l'entreprise historiographique "souvent soumise aux exigences d'une méthodologie positiviste ». Anne-Marie Paquet-Deyris analyse un récit de Gloria Naylor, dont l'action se situe dans une île ne figurant sur aucune carte. Marc Mve Bekale appréhende à travers la notion de perte des coordonnées spatio-temporelles l'histoire de la traversée transatlantique des Africains dans les romans de Charles Johnson et Fred d'Aguiar. Arlette Frund, enfin, explore les formes narratives concourant à construire un espace féminin dans deux ouvrages d'Edwige Danticat.

8 Un travail de cent quatre vingt cinq pages ne saurait tout dire et l'on regrettera peut être que n'apparaisse pas le nom de Marvin A Lewis, pionnier des recherches sur l'histoire littéraire de la diaspora africaine de langue latine ou celui de Patricia Bell Scott coéditrice d'ouvrages féministes noirs américains essentiels. Mais les notes de références, bibliographies et rappels de dates importantes couvrent un vaste champ.

9 «Ecritures de l'histoire africaine américaine» est intéressant par son esprit d'ouverture, par la rigueur de son contenu et par une genèse qui explique en partie les deux: l'ouvrage est issu des rencontres internationales du Cercle d'Etudes AfroAméricaines (CEAA), association inter-universitaire fondée par Geneviève et Michel Fabre. Depuis la fin des années soixante les fondateurs et les membres du bureau scientifique du Cercle incitent les spécialistes de la communauté noire à en réexaminer l'histoire à travers les outils propres à leur discipline, qu'il s'agisse de sociologie, de musique, de poésie ou de théâtre. Ce livre qui génère de multiples possibilités d'interprétation est donc une nouvelle étape dans un cheminement collectif, et, puisque "écritures de l'histoire africaine américaine" s'ouvre sur plusieurs articles soucieux de rendre à la sensibilité, au silence et à l'émotion leur juste place en tant que données historiques, peut-être est il permis de rappeler que ce travail est lui même le fruit d'une longue histoire de partage et d'amitié entre chercheurs et qu'on pourrait ici parler de convergence des cœurs autant que des savoirs. 
INDEX

Thèmes : Recensions

\section{AUTEUR}

ALICE MILLS

Université de Caen 